\title{
Ornamental bromeliads of Miami-Dade County, Florida are important breeding sites for Aedes aegypti (Diptera: Culicidae)
}

\author{
André B. B. Wilke ${ }^{1 *}$, Chalmers Vasquez ${ }^{2}$, Paul J. Mauriello $0^{2,3}$ and John C. Beier ${ }^{1}$
}

\begin{abstract}
Background: A major public health concern is the emergence and geographical spread of vector-borne diseases such as Zika and yellow fever. Ornamental bromeliads retaining water in their leaf axils represent potential breeding sites for mosquitoes. As the role of ornamental bromeliads in breeding Aedes aegypti in Miami-Dade County, Florida is unknown, we hypothesize that ornamental bromeliads are important breeding sites for Ae. aegypti. Our objective was to survey bromeliads in areas with high densities of adult Ae. aegypti, including those with 2016 local transmission of Zika virus.

Methods: Ornamental bromeliads were surveyed for the presence of immature mosquitoes at 51 locations of Miami-Dade County, Florida. Bromeliads were sampled for the presence of immature stages of mosquitoes, their reservoirs were drained and screened for the presence of immature mosquitoes. Immature mosquitoes were stored in plastic containers and preserved in 70\% ethanol until morphological identification. Biodiversity of species assemblages was assessed by Shannon's and Simpson's indices, and individual rarefaction curves and plots of cumulative abundance, Shannon's index and evenness profiles.
\end{abstract}

Results: Ornamental bromeliads were present in all surveyed areas, yielding a total of 765 immature mosquitoes, comprising five taxonomic units: Ae. aegypti, Wyeomyia mitchellii, Wyeomyia vanduzeei, Culex quinquefasciatus and Culex biscaynensis. The biodiversity indices point to a low diversity scenario with a highly dominant species, Ae. aegypti.

Discussion: Our findings suggest that ornamental bromeliads are contributing for the proliferation of Ae. aegypti in the County of Miami-Dade, which may indicate a shift in the paradigm of usage of bromeliads as breeding sites, highlighting that ornamental phytotelmata bromeliads are to be considered in future vector-control strategies to control Zika and other arboviruses.

Keywords: Vector ecology, Urbanization, Bromeliaceae, Zika virus

\section{Background}

Vector-borne diseases are an increasing public health concern, they are spreading to new areas due to urbanization, human movement and global warming [1-3]. Anthropogenic alterations in the environment are positively associated with the decrease in richness and increase in abundance of selected species of vector mosquitoes that are adapted to live in the

\footnotetext{
* Correspondence: axb1737@med.miami.edu

${ }^{1}$ Department of Public Health Sciences, Miller School of Medicine, University of Miami, Miami, FL, USA

Full list of author information is available at the end of the article
}

urban environment, significantly impacting the risk of vector-borne disease transmission [4-6].

Substantial efforts have been made to control Aedes aegypti mosquitoes, a highly invasive species with worldwide distribution and highly adapted to urban environments. It is often positively associated with human population densities, laying eggs in artificial breeding sites and blood-feeding in human hosts. Moreover, Ae. aegypti is the main vector for dengue fever (DENV), chikungunya (CHYKV), yellow fever (YFV) and Zika (ZIKV) viruses [6-10]. Recently, it was responsible for the spreading of ZIKV in the Americas resulting in more

(c) The Author(s). 2018 Open Access This article is distributed under the terms of the Creative Commons Attribution 4.0 International License (http://creativecommons.org/licenses/by/4.0/), which permits unrestricted use, distribution, and 
than 700,000 cases, and subsequent introduction in the USA, resulting in hundreds of reported cases of local transmission in the County of Miami-Dade, Florida [11, 12].

The (re-)emergence and spreading of vector-borne diseases such as YFV and ZIKV is inevitable [13-15], and according to the World Health Organization (WHO) integrated vector management (IVM) is the most effective and sustainable strategy for the prevention of vector-borne diseases. IVM consists of scientific driven decision-making process to increase the effectiveness of the available resources for vector control, including traditional and new strategies that can be adapted to the target species such as Ae. aegypti, Anopheles gambiae and Culex quinquefasciatus [16-18]. Consisting of the use of both chemical and non-chemical control strategies, the IVM prioritize active surveillance of vector-mosquitoes, removal of breeding sites and campaigns for population consciousness [19]. Moreover, human behavior is a key driver for the population dynamics of Ae. aegypti, structural man-made alterations in the urban landscape commonly found around households are excellent breeding sites to their immatures [20-22].

Plants such as bromeliads are a popular choice for landscaping projects, widely found throughout urban areas since they are very resilient and do not need much care. Bromeliads (Bromeliaceae) are a family of Neotropical plants, composed by around 50 genera and more than three thousand species, they are capable of absorbing nutrients from the water retained in their leaves axils and central tank, sheltering several species of insects, some of them with epidemiological relevance [23]. Anopheline species, mostly from the subgenus Kerteszia, have phytotelmata bromeliads as primary breeding sites, rendering these plants important for the epidemiology of malaria $[24,25]$.

Ornamental bromeliads comprise a complex scenario in which the composition of mosquito species vary locally, often affected by heavy rainfall and seasonality. Furthermore, the role of ornamental bromeliads in breeding Ae. aegypti has been considered unimportant by several studies [26-28]. However, intense selective pressures present in urbanized areas may be modulating behavioral changes in Ae. aegypti. Previous studies found that urban populations are laying eggs in brackish water and sewage, indicating adaptations to new breeding sites $[29,30]$.

The Miami-Dade County Mosquito Control Division has greatly intensified vector-mosquito suppression efforts since the ZIKV outbreak in 2016. This includes considering the potential risk of ornamental bromeliads breeding vector mosquitoes, applying insecticides, removing plants when necessary, in addition to issuing brochures to notify and educate the public (Additional file 1: Figure S1). However, scientific evidence whether $A$ e. aegypti and other vector mosquitoes are breeding in ornamental bromeliads is lacking for Miami-Dade County, as well as how vector mosquito population dynamics has been driven by the presence of these plants.

An understanding of how vector mosquitoes are adapting locally to ornamental bromeliads is needed by Miami-Dade Mosquito Control Division to locally tailor surveillance-response programs. Taking this into account, our hypothesis is that ornamental bromeliads commonly used for landscaping purposes in MiamiDade County, Florida are important breeding sites for Ae. aegypti. Therefore, our objective was to survey bromeliads in urbanized areas with high densities of $A e$. aegypti, including those with previous local transmission of ZIKV.

\section{Methods}

The 51 study locations were selected for the surveybased bromeliad study because of their unique socioeconomic and environmental characteristics including normalized difference vegetation index (NDVI), income and the risk of vector-borne disease transmission as previously described [31-33]. This allowed us to capture variation among the 11 neighborhoods and 18 ZIP Codes in which the 51 locations were situated in Miami-Dade County, Florida as well as the distinctive conditions for mosquito proliferation and high densities of adult $A e$. aegypti. Three of the 11 study locations were neighborhoods with 2016 local transmission of Zika virus (South Beach, Wynwood and Little River) (Fig. 1). Ornamental bromeliads were surveyed once a week for five weeks between June and July 2017 for the presence of immature mosquitoes.

Aiming for a wide coverage area, all bromeliad plants in each area were sampled for the presence of immature stages of mosquitoes. The sampling effort was standardized for all collections, consisting of draining bromeliads' water reservoir tanks with the aid of manual plastic pumps (turkey basters). Water samples were then inspected for the presence of immature mosquitoes and stored in plastic containers $(100 \mathrm{ml})$ for transport. All the material collected was transported to the Miami-Dade County Mosquito Control Laboratory, immature mosquitoes were preserved in $70 \%$ ethanol and subsequently morphologically identified using taxonomic keys [34].

Biodiversity indices for the collected mosquitoes were calculated based on the Shannon's diversity index [35] and Simpson's dominance index [36]. Individual rarefaction curves were generated to estimate both sampling sufficiency and expected occurrence of species for smaller samples. The test requirements for taxonomic proximity of samples, standardized sampling effort and collection in similar habitats were met [37]. Plots of cumulative species 


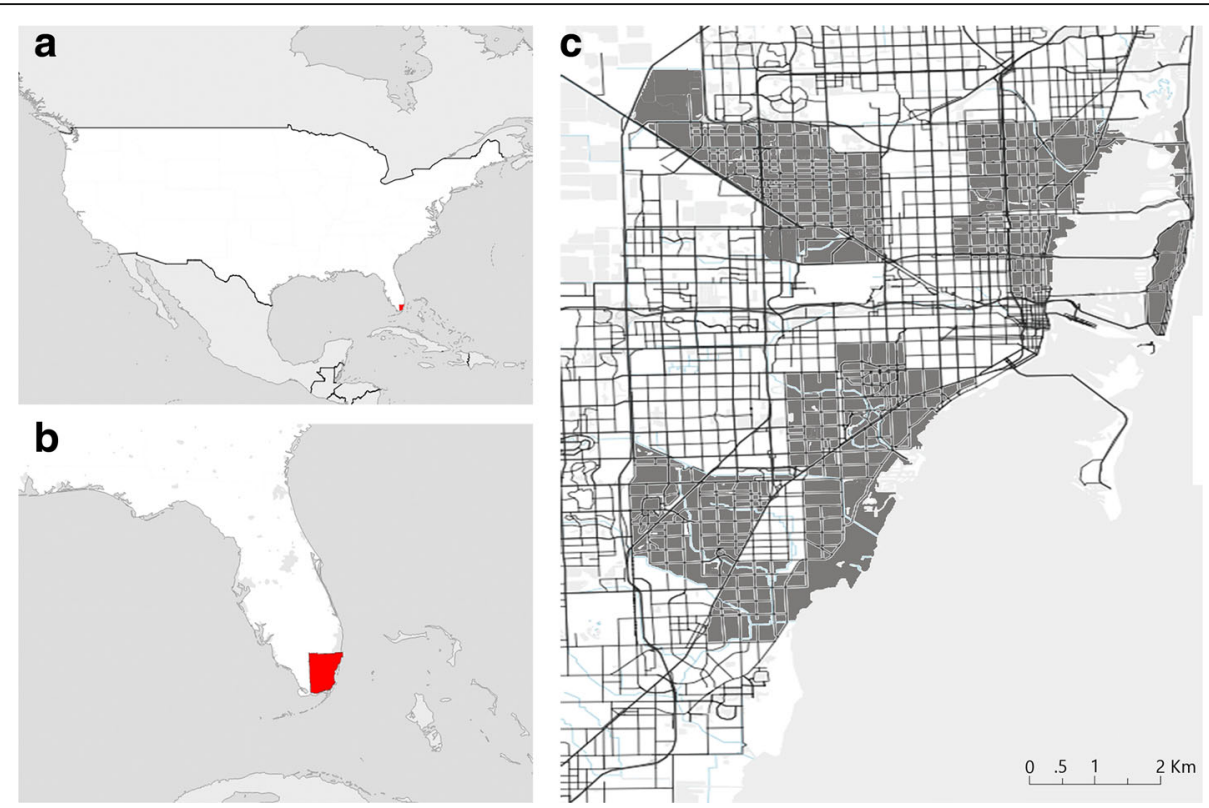

Fig. 1 Maps showing surveyed areas for immature mosquitoes breeding in ornamental bromeliads in the County of Miami-Dade. a North America. b Southeast United States. c Miami-Dade County

abundance (ln S), Shannon's index $(\mathrm{H})$ and log evenness (ln E) (SHE) profiles were also calculated for the collected immature mosquitoes. Changes in direction of lines indicate ecological heterogeneity of mosquito assembly [38]. All analyses were carried out with 10,000 randomizations without replacement and 95\% confidence interval using the Past software (v.3.16) [39].

\section{Results}

Ornamental bromeliads were abundantly found at all 51 locations surveyed, being present in residential, commercial and public areas. Moreover, they are popular among landscaping in residential areas, accumulating water and serving as breeding sites for vector mosquitoes (Fig. 2).

A total of 765 immature mosquitoes were collected from ornamental bromeliads water reservoirs, comprising three mosquito genera, Aedes (Meigen), Culex (Linnaeus) and Wyeomyia (Theobald), and five taxonomic units Ae. aegypti, Wyeomyia mitchellii, Wyeomyia vanduzeei, Cx. quinquefasciatus and Culex biscaynensis. No predator invertebrates were found preying on immature mosquitoes breeding in ornamental bromeliads. Furthermore, Ae. aegypti was the most abundant species found breeding in bromeliads, accounting for around $40 \%$ of all specimens collected, followed by Cx. quinquefasciatus, Wy. vanduzeei, Wy. mitchellii and Cx. biscaynensis. Aedes aegypti also had the highest incidence, being collected in 13 from 18 ZIP Code areas surveyed (Table 1).

The Shannon's diversity index had an average of 1.38 (95\% CI: 1.19-1.50), indicating low degrees of species diversity in bromeliads (Fig. 3a). Similar results were found for the Simpson's index, indicating Ae. aegypti as the most dominant species breeding in bromeliads, yielding a value of 0.85 (95\% CI: $0.84-0.87$ ) (Fig. 3b). The individual rarefaction curves indicated that sampling sufficiency was considerably asymptotic for all species but $C x$. biscaynensis, with a substantial degree of confidence for predicting the expected presence of those species for smaller sample sizes (Fig 3c). The changes in direction of the lines in the cumulative SHE analysis revealed the heterogeneity of species composition, diversity and evenness for the immature mosquitoes found breeding in bromeliads in different areas (Fig. 3d).

\section{Discussion}

Bromeliads plants embody a complex scenario, in which their importance in breeding vector-mosquitoes may vary according to locality, habitats, vector species, human behavior and climate [23]. Our findings suggest that ornamental bromeliads are contributing for the proliferation of Ae. aegypti in the County of Miami-Dade. The analysis revealed a low diversity scenario, in which Ae. aegypti is the most dominant species breeding in bromeliads as well as the most likely to be found in these plants. Moreover, notwithstanding the great variation found for the mosquito community structure, Ae. aegypti was the least affected species exhibiting a higher incidence and abundance among the species found in bromeliads. In addition, Aedes albopictus were not found breeding in ornamental bromeliads; however, this result may be explained by its relatively low occurrence in Miami-Dade County. According to the Miami-Dade Mosquito Control Division, from 


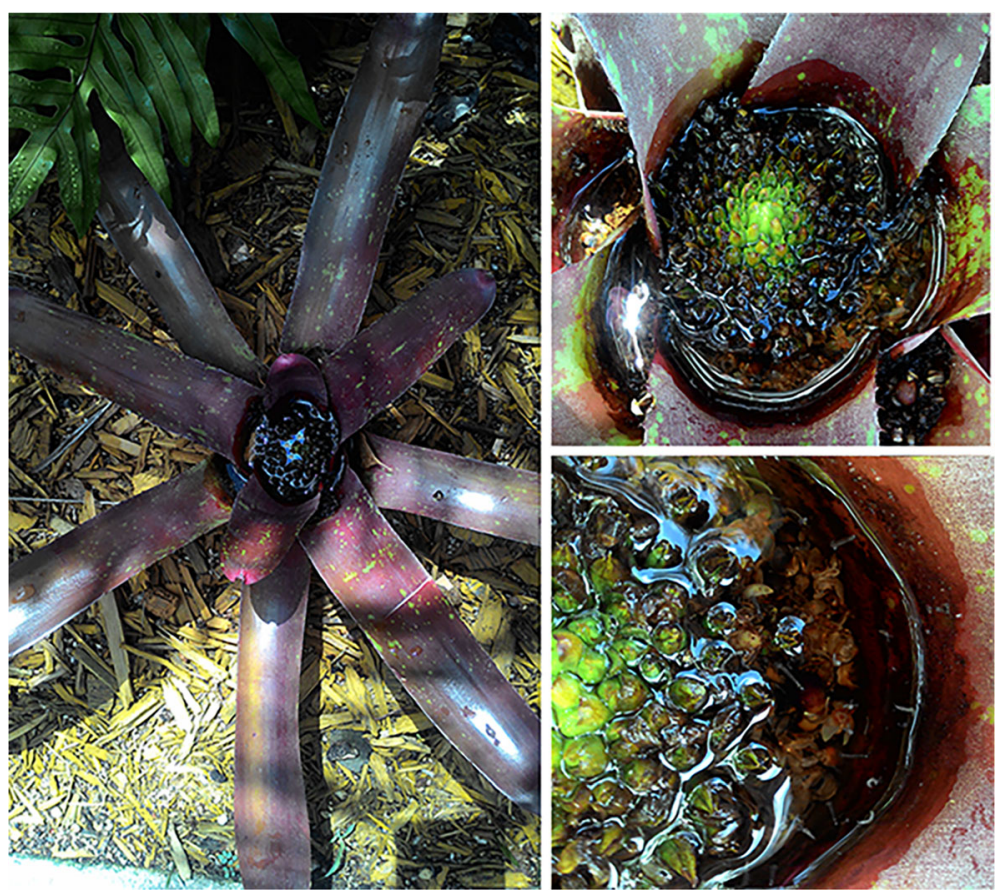

Fig. 2 Ornamental bromeliads breeding vector mosquitoes

Table 1 Immature mosquito species collected in ornamental bromeliads in the County of Miami-Dade

\begin{tabular}{|c|c|c|c|c|c|c|c|c|}
\hline Neighborhood & Income ${ }^{a}$ & ZIP code & $\begin{array}{l}\text { Aedes (Ste.) } \\
\text { aegypti }\end{array}$ & $\begin{array}{l}\text { Wyeomyia (Wye.) } \\
\text { mitchellii }\end{array}$ & $\begin{array}{l}\text { Wyeomyia (Wye.) } \\
\text { vanduzeei }\end{array}$ & Wyeomyia sp. & $\begin{array}{l}\text { Culex (Cux.) } \\
\text { quinquefasciatus }\end{array}$ & $\begin{array}{l}\text { Culex (Cux.) } \\
\text { biscaynensis }\end{array}$ \\
\hline Hialeah & Low & 33010 & 20 & 0 & 108 & 0 & 0 & 0 \\
\hline Hialeah & Low & 33012 & 5 & 0 & 4 & 0 & 0 & 0 \\
\hline Hialeah & Low & 33013 & 6 & 0 & 6 & 0 & 0 & 0 \\
\hline Wynwood & Low & 33127 & 0 & 0 & 0 & 0 & 0 & 0 \\
\hline Coconut Grove & High & 33133 & 36 & 0 & 6 & 0 & 32 & 0 \\
\hline Coral Gables & High & 33134 & 57 & 0 & 2 & 0 & 42 & 0 \\
\hline Wynwood & Low & 33137 & 17 & 0 & 12 & 0 & 0 & 0 \\
\hline South Beach & Medium & 33139 & 9 & 0 & 0 & 0 & 0 & 0 \\
\hline Mid Beach & Medium & 33140 & 0 & 12 & 0 & 0 & 0 & 0 \\
\hline Lagorce Island & High & 33141 & 1 & 0 & 0 & 1 & 0 & 0 \\
\hline Kendall & Medium & 33143 & 28 & 1 & 3 & 0 & 0 & 7 \\
\hline Coral Gables & High & 33146 & 45 & 0 & 0 & 0 & 86 & 0 \\
\hline Palmetto Bay & High & 33157 & 5 & 85 & 8 & 0 & 1 & 6 \\
\hline Coral Gables & High & 33158 & 67 & 0 & 2 & 0 & 3 & 6 \\
\hline Miami Springs & Medium & 33166 & 0 & 11 & 1 & 2 & 0 & 0 \\
\hline Kendall & Medium & 33173 & 0 & 2 & 7 & 0 & 0 & 1 \\
\hline Kendall & Medium & 33176 & 0 & 0 & 4 & 0 & 0 & 2 \\
\hline \multirow[t]{2}{*}{ Biscayne Bay } & High & 33181 & 5 & 0 & 0 & 0 & 1 & 0 \\
\hline & & & 301 & 111 & 163 & 3 & 165 & 22 \\
\hline
\end{tabular}

aased on median household income (in 2016 dollars), 2012-2016. US Census Bureau [33] 

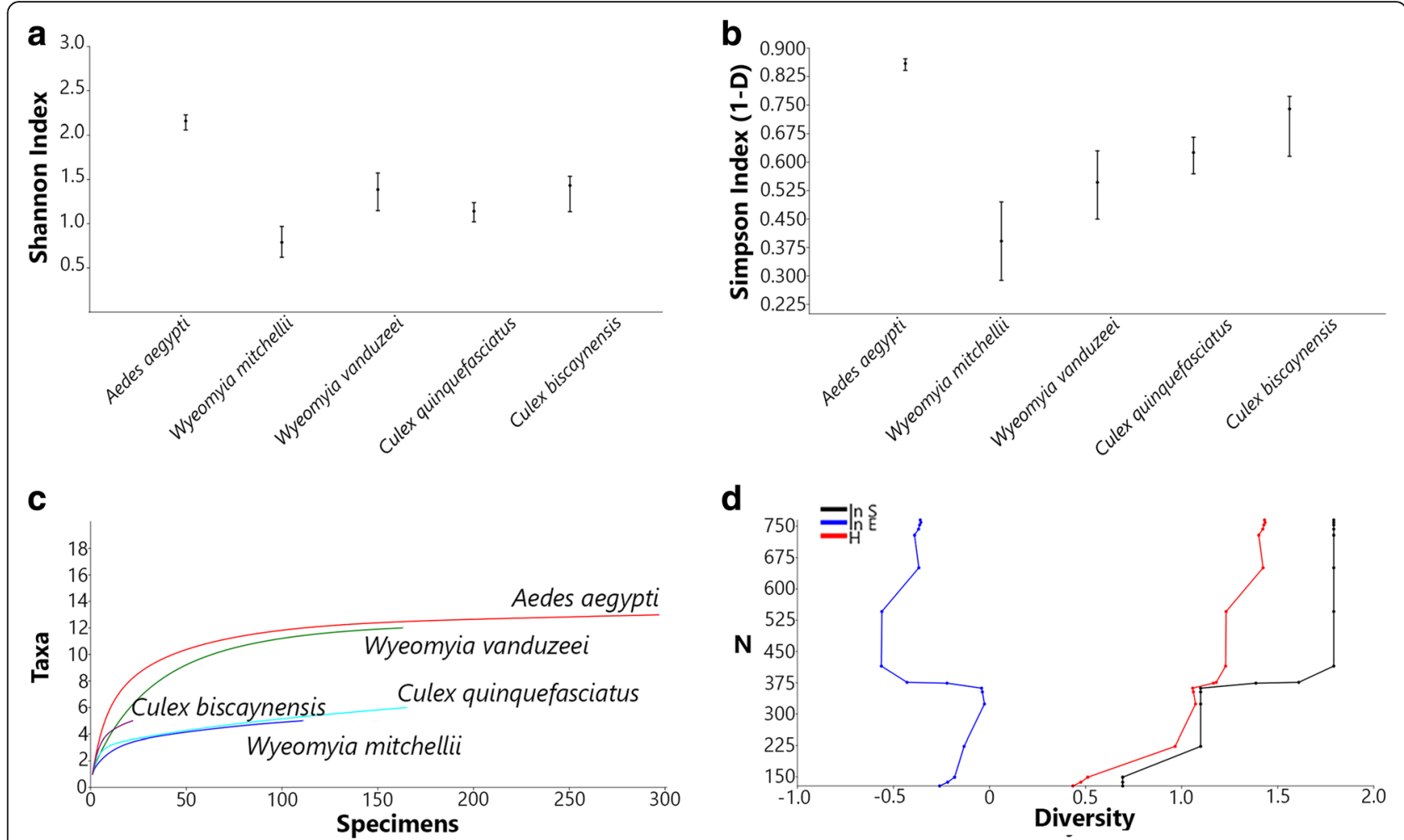

Fig. 3 Biodiversity indices for immature mosquitoes collected from ornamental bromeliads in Miami-Dade County. a Shannon's index (H). b Simpson's (1-D) index. c Individual rarefaction curves; d Plots of cumulative SHE profiles (In S, H and In E)

January to August 2017, 25,946 specimens of Ae. aegypti were collected, contrasting with only 380 specimens of $A e$. albopictus collected during the same period.

The results obtained in this study contrast with previous studies, which do not consider bromeliads as important potential breeding sites for Ae aegypti [26, 28, 40], including for South Florida [41]. However, MiamiDade County has been undergoing intense efforts to control vector mosquitoes, employing both chemical and biological strategies, as well as breeding site removal as part of IVM strategies, which may translate as strong selective pressures for Ae. aegypti populations that may be leading to a shift in their behavior and triggering adaptation processes. The fact that immature Ae. aegypti had been more abundantly found breeding in bromeliads than Wy. mitchellii and Wy. vanduzeei, considered adapted to breed in plants from the family Bromeliaceae, with implications to local control strategies. Also, the fact that no predator has been found preying on immature mosquitoes breeding in ornamental bromeliads constitutes a habitat in which vector-mosquitoes can potentially grow indiscriminately, positively driving their abundance.

Nevertheless, our results should be interpreted with caution since vector mosquitoes breeding in bromeliads comprise a complex scenario with wide variation between environments and localities, resulting in the impossibility of transposing our findings for another area besides Miami-Dade County. Additionally, the cross-sectional experimental design without re-sampling chosen for this study may have resulted in the underestimation for the abundance of vector-mosquitoes as well as not having been able to detect rare species breeding in ornamental bromeliads.

In view of the Miami-Dade scenario, there are very few options to prevent ornamental bromeliads from becoming potential breeding sites for vector mosquitoes. Granules or pellets containing the insect growth regulator (S)-methoprene have been successfully used for controlling Ae. aegypti immatures in bromeliads [42], commercial larvicides based on toxins extracted from Bacillus thuringiensis israelensis (Bti) are also available. However, ornamental bromeliads are highly abundant and the fact that every plant must be treated frequently hampers the process. Flushing the water accumulated in plants reservoirs with a hose is also unlikely to prevent mosquitoes from breeding since it is virtually impossible to reach to every single water reservoir and remove all larvae. Moreover, there is an inherent risk to this scenario due to the use of ornamental bromeliads in landscaping in densely populated areas, where reduced overall biodiversity of urban areas results in fewer availability of hosts for blood-feeding, favoring anthropophilic species of 
mosquitoes, and consequently increasing the risk of vector-borne diseases.

\section{Conclusions}

The ZIKV outbreak that struck Miami in 2016 created panic among the public, greatly impacting the economy and endangering residents and tourists. The present study provides evidence that the County responded appropriately during the ZIKV outbreak crisis. Our scientific findings exposed an unexpected scenario for Miami-Dade County, in which Ae. aegypti immatures are successfully breeding in ornamental bromeliads. To our understanding, it is recommended that during emergency situations control methods should be employed systematically on phytotelmata bromeliads, and removal of plants should be considered when needed.

\section{Additional file}

Additional file 1: Figure S1. Miami-Dade County Mosquito Control Div ision brochure alerting for the risk of ornamental bromeliads as potential breeding sites for vector-mosquitoes. Available in: https://www.miamidade.gov/solidwaste/library/brochures/bromeliads-and-mosquitoes.pdf. (TIF $3033 \mathrm{~kb}$ )

\section{Abbreviations}

Bti: Bacillus thuringiensis israelensis; CHYKV: Chikungunya virus; DENV: Dengue fever virus; IVM: Integrated vector management; WHO: World Health Organization; YFV: Yellow fever virus; ZIKV: Zika virus

\section{Acknowledgements}

We would like to thank the residents of Miami-Dade County who graciously allowed us to enter their properties. We are grateful to staff of Miami-Dade County Mosquito Control Division for their help with field collections.

\section{Funding}

This research was supported by CDC (https://www.cdc.gov/) grant 1U01CK000510-01: Southeastern Regional Center of Excellence in VectorBorne Diseases: The Gateway Program. CDC had no role in the design of the study and collection, analysis, and interpretation of data and in writing the manuscript.

\section{Availability of data and materials}

All data generated or analyzed during this study are included in this published article and its additional file.

\section{Authors' contributions}

ABBW, CV, PM and JCB designed the study. ABBW and JCB carried out the experiments and data analysis. ABBW, CV, PM and JCB drafted the manuscript and critically revised it. All authors read and approved the final manuscript.

\section{Ethics approval}

Because the study poses less than minimal risk to participants the Institutional Review Board at the University of Miami determined that the study was exempt from institutional review board assessment (IRB Protocol Number: 20161212)

\section{Competing interests}

The authors declare that they have no competing interests.

\section{Publisher's Note}

Springer Nature remains neutral with regard to jurisdictional claims in published maps and institutional affiliations.

\section{Author details}

'Department of Public Health Sciences, Miller School of Medicine, University of Miami, Miami, FL, USA. ${ }^{2}$ Miami-Dade County Mosquito Control Division, Miami, FL, USA. ${ }^{3}$ Miami-Dade County Department of Solid Waste Management, Miami, FL, USA.

Received: 18 January 2018 Accepted: 23 April 2018

Published online: 17 May 2018

\section{References}

1. Hemme RR, Thomas CL, Chadee DD, Severson DW. Influence of urban landscapes on population dynamics in a short-distance migrant mosquito: evidence for the dengue vector Aedes aegypti. PLoS Negl Trop Dis. 2010;4:1-9.

2. Ferraguti M, Martínez-de la Puente J, Roiz D, Ruiz S, Soriguer R, Figuerola J. Effects of landscape anthropization on mosquito community composition and abundance. Sci Rep. 2016;6:29002.

3. World Health Organization. Zika Strategic Response Plan: Updated 30 June 2016. 2016. Geneva: World Health Organization; 2016. p. 50.

4. McKinney ML. Urbanization as a major cause of biotic homogenization. Biol Conserv. 2006;127:247-60.

5. Knop E. Biotic homogenization of three insect groups due to urbanization. Glob Chang Biol. 2016;22:228-36.

6. Gubler DJ. Dengue, urbanization and globalization: the unholy trinity of the 21st Century. Trop Med Health. 2011;39:S3-11.

7. Brown JE, Evans BR, Zheng W, Obas V, Barrera-Martinez L, Egizi A, et al. Human impacts have shaped historical and recent evolution in Aedes aegypti, the dengue and yellow fever mosquito. Evolution. 2014;68:514-25.

8. Couto-Lima D, Madec Y, Bersot MI, Campos SS, Motta M de A, dos Santos $\mathrm{FB}$, et al. Potential risk of re-emergence of urban transmission of yellow fever virus in Brazil facilitated by competent Aedes populations. Sci Rep. 2017;7:4848.

9. Costa-da-Silva AL, loshino RS, Petersen V, Lima AF, Cunha M dos P Wiley MR, et al. First report of naturally infected Aedes aegypti with chikungunya virus genotype ECSA in the Americas. PLoS Negl Trop Dis. 2017;11:e0005630

10. Faria NR, Quick J, Claro IM, Thézé J, de Jesus JG, Giovanetti M, et al. Establishment and cryptic transmission of Zika virus in Brazil and the Americas. Nature. 2017:546:406-10.

11. Zhang Q, Sun K, Chinazzi M, Pastore y Piontti A, Dean NE, Rojas DP, et al. Spread of Zika virus in the Americas. Proc Natl Acad Sci USA. 2017;114: E4334-43.

12. Likos A, Griffin I, Bingham AM, Stanek D, Fischer M, White S, et al. Local mosquito-borne transmission of Zika virus - Miami-Dade and Broward Counties, Florida, June-August 2016. MMWR Morb Mortal Wkly Rep. 2016;65: $1032-8$

13. Chen LH, Wilson ME, et al. Med Clin North Am. 2008;92:1409-32.

14. Paules $\mathrm{Cl}$, Fauci AS. Yellow fever - once again on the radar screen in the Americas. N Engl J Med. 2017;376:1397-9.

15. Etienne C, Espinal MA, dos Santos T. Zika virus disease in the Americas: a storm in the making. Am J Trop Med Hyg. 2017;97:16-8.

16. World Health Organization. Global strategic framework for integrated vector management. Geneva: WHO; 2004. p. 10.

17. Beier JC, Keating J, Githure J, Macdonald MB, Impoinvil DE, Novak RJ. Integrated vector management for malaria control. Malar J. 2008;7:S4.

18. Lizzi KM, Qualls WA, Brown SC, Beier JC. Expanding integrated vector management to promote healthy environments. Trends Parasitol. 2014;30:394-400.

19. WHO. Handbook for integrated vector management. Outlooks Pest Manag. 2013;24:142-3.

20. Chadee DD, Martinez R. Aedes aegypti (L.) in Latin American and Caribbean region: with growing evidence for vector adaptation to climate change? Acta Trop. 2016;156:137-43.

21. Guagliardo SA, Barboza JL, Morrison AC, Astete H, Vazquez-Prokopec G, Kitron U. Patterns of geographic expansion of Aedes aegypti in the Peruvian Amazon. PLoS Negl Trop Dis. 2014;8:e3033.

22. Quintero J, Brochero H, Manrique-Saide P, Barrera-Pérez M, Basso C, Romero S, et al. Ecological, biological and social dimensions of dengue vector breeding in five urban settings of Latin America: a multi-country study. BMC Infect Dis. 2014;14:38. 
23. Frank JH, Lounibos LP. Insects and allies associated with bromeliads: a review. Terr Arthropod Rev. 2009;1:125-53.

24. de Pina-Costa A, Brasil P, Di Santi SM, de Araujo MP, Suárez-Mutis MC, Santelli ACF, et al. Malaria in Brazil: what happens outside the Amazonian endemic region. Mem Inst Oswaldo Cruz. 2014;109:618-33.

25. Marrelli MT, Malafronte RS, Sallum MA, Natal D. Kerteszia subgenus of Anopheles associated with the Brazilian Atlantic rainforest: current knowledge and future challenges. Malar J. 2007;6:127.

26. Mocellin MG, Simões TC, do TFS N, MLF T, Lounibos LP, de Oliveira RL, et al. Bromeliad-inhabiting mosquitoes in an urban botanical garden of dengue endemic Rio de Janeiro - are bromeliads productive habitats for the invasive vectors Aedes aegypti and Aedes albopictus? Mem Inst Oswaldo Cruz. 2009;104:1171-6.

27. Maciel-de-Freitas R, Marques WA, Peres RC, Cunha SP, De Oliveira RL. Variation in Aedes aegypti (Diptera: Culicidae) container productivity in a slum and a suburban district of Rio de Janeiro during dry and wet seasons. Mem Inst Oswaldo Cruz. 2007;102:489-96.

28. Santos $C B$, Leite $G R$, Falqueto $A$. Does native bromeliads represent important breeding sites for Aedes aegypti (L.) (Diptera: Culicidae) in urbanized areas? Neotrop Entomol. 2011;40:278-81.

29. Ramasamy R, Surendran SN, Jude PJ, Dharshini S, Vinobaba M. Larval development of Aedes aegypti and Aedes albopictus in peri-urban brackish water and its implications for transmission of arboviral diseases. PLoS Negl Trop Dis. 2011;5:e1369.

30. Chitolina RF, Anjos FA, Lima TS, Castro EA, Costa-Ribeiro MCV. Raw sewage as breeding site to Aedes (Stegomyia) aegypti (Diptera, culicidae). Acta Trop. 2016;164:290-6.

31. Brown SC, Lombard J, Wang K, Byrne MM, Toro M, Plater-Zyberk E, et al. Neighborhood greenness and chronic health conditions in medicare beneficiaries. Am J Prev Med. 2016;51:78-89.

32. Ajelli M, Moise IK, Hutchings TCSG, Brown SC, Kumar N, Johnson NF, Beier JC. Host outdoor exposure variability affects the transmission and spread of Zika virus: insights for epidemic control. PLoS Negl Trop Dis. 2017;11: e0005851.

33. Census Bureau. https://www.census.gov/topics/income-poverty/income. html. Accessed 12 Feb 2018.

34. Darsie, Jr. RF, Morris CD. Keys to the adult females and fourth-instar larvae of the mosquitoes of Florida (Diptera, Culicidae). 1st ed. Vol. 1. Tech Bull Florida Mosa Cont Assoc; 2000.

35. Shannon CE. A mathematical theory of communication. Bell Syst Tech J. 1948:27:379-423.

36. Simpson EH. Measurement of diversity. Nature. 1949;163:688.

37. Colwell RK, Chao A, Gotelli NJ, Lin SY, Mao CX, Chazdon RL, et al. Models and estimators linking individual-based and sample-based rarefaction, extrapolation and comparison of assemblages. J Plant Ecol. 2012;5:3-21.

38. Buzas MA, Hayek LAC. SHE analysis for biofacies identification. J Foraminifer Res. 1998;28:233-9.

39. Hammer $\varnothing$, Harper DATT, Ryan PD. PAST. Paleontological Statistics Software Package for Education and Data Analysis. Palaeontol Electron. 2001;4:9.

40. Talaga S, Dézerald O, Carteron A, Leroy C, Carrias J-F, Céréghino R, et al. Urbanization impacts the taxonomic and functional structure of aquatic macroinvertebrate communities in a small neotropical city. Urban Ecosyst. 2017;20:1001-9

41. O'Meara GF, Cutwa MM, Evans LF. Bromeliad-inhabiting mosquitoes in south Florida: native and exotic plants differ in species composition. J Vector Ecol. 2003;28:37-46.

42. Ritchie SA, Broadsmith G. Efficacy of ALTOSID pellets and granules against Aedes aegypti in ornamental bromeliads. J Am Mosq Control Assoc. 1997;13: 201-2.

\section{Ready to submit your research? Choose BMC and benefit from:}

- fast, convenient online submission

- thorough peer review by experienced researchers in your field

- rapid publication on acceptance

- support for research data, including large and complex data types

- gold Open Access which fosters wider collaboration and increased citations

- maximum visibility for your research: over $100 \mathrm{M}$ website views per year

At BMC, research is always in progress.

Learn more biomedcentral.com/submissions 